\title{
Activation of EGFR-DNA-PKcs pathway by IGFBP2 protects esophageal adenocarcinoma cells from acidic bile salts- induced DNA damage
}

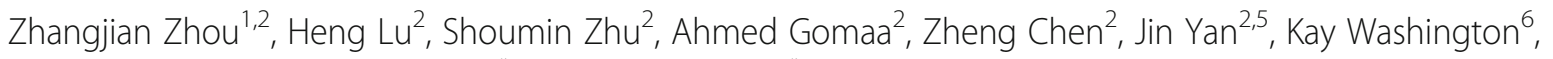
Wael El-Rifai ${ }^{2,3,4}$, Chengxue Dang ${ }^{1 *}$ and Dunfa Peng ${ }^{2,3^{*}}$ (i)

\begin{abstract}
Background: The incidence of esophageal adenocarcinoma (EAC) is rising rapidly in the US and Western countries. The development of Barrett's esophagus (BE) and its progression to EAC have been linked to chronic gastroesophageal reflux disease (GERD). Exposure of BE and EAC cells to acidic bile salts (ABS) in GERD conditions induces high levels of oxidative stress and DNA damage. In this study, we investigated the role of insulin-like growth factor binding protein 2 (IGFBP2) in regulating ABS-induced DNA double-strand breaks.

Methods: Real-time RT-PCR, western blot, immunohistochemistry, immunofluorescence, co-immunoprecipitation, flow cytometry, and cycloheximide (CHX) chase assays were used in this study. To mimic GERD conditions, a cocktail of acidic bile salts ( $\mathrm{pH} 4$ ) was used in $2 \mathrm{D}$ and 3D organotypic culture models. Overexpression and knockdown of IGFBP2 in EAC cells were established to examine the functional and mechanistic roles of IGFBP2 in ABS-induced DNA damage.

Results: Our results demonstrated high levels of IGFBP2 mRNA and protein in EAC cell lines as compared to precancerous Barrett's cell lines, and IGFBP2 is frequently overexpressed in EACs (31/57). Treatment of EAC cells with ABS, to mimic GERD conditions, induced high levels of IGFBP2 expression. Knocking down endogenous IGFBP2 in FLO1 cells (with constitutive high levels of IGFBP2) led to a significant increase in DNA double-strand breaks and apoptosis, following transient exposure to ABS. On the other hand, overexpression of exogenous IGFBP2 in OE33 cells (with low endogenous levels of IGFBP2) had a protective effect against ABS-induced double-strand breaks and apoptosis. We found that IGFBP2 is required for ABS-induced nuclear accumulation and phosphorylation of EGFR and DNA-PKcs, which are necessary for DNA damage repair activity. Using co-immunoprecipitation assay, we detected co-localization of IGFBP2 with EGFR and DNA-PKCs, following acidic bile salts treatment. We further demonstrated, using cycloheximide chase assay, that IGFBP2 promotes EGFR protein stability in response to ABS exposure.
\end{abstract}

Conclusions: IGFBP2 protects EAC cells against ABS-induced DNA damage and apoptosis through stabilization and activation of EGFR - DNA-PKCs signaling axis.

Keywords: IGFBP2, EGFR, DNA-PKcs, DNA damage, Acidic bile salts, Esophageal adenocarcinoma

\footnotetext{
* Correspondence: dangchengxue@mail.xjtu.edu.cn;

dunfa.peng@med.miami.edu

${ }^{1}$ Department of Surgical Oncology, the First Affiliated Hospital of Xi'an

Jiaotong University, 277 Yanta W. Road, Xi'an 710061, Shaanxi, China

${ }^{2}$ Department of Surgery, University of Miami Miller School of Medicine,

Miami, FL 33136-1015, USA

Full list of author information is available at the end of the article
}

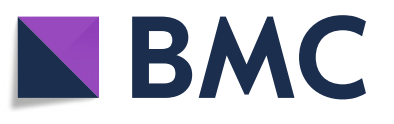

(c) The Author(s). 2019 Open Access This article is distributed under the terms of the Creative Commons Attribution 4.0 International License (http://creativecommons.org/licenses/by/4.0/), which permits unrestricted use, distribution, and reproduction in any medium, provided you give appropriate credit to the original author(s) and the source, provide a link to the Creative Commons license, and indicate if changes were made. The Creative Commons Public Domain Dedication waiver (http://creativecommons.org/publicdomain/zero/1.0/) applies to the data made available in this article, unless otherwise stated. 


\section{Background}

Over the past few decades, the incidence of esophageal adenocarcinoma (EAC) has increased rapidly in the United States and Western countries [1, 2]. Abnormal exposure of esophageal cells to a mixture of acid and bile salts in patients with chronic gastroesophageal reflux disease (GERD) is a major risk factor for the development of pre-malignant Barrett's esophagus $(\mathrm{BE})$ and its progression to EAC $[3,4]$. Previous studies have shown that exposure to acidic bile salts (ABS) induces DNA damage in BE and EAC cells [5-7]. Accumulation of unrepaired DNA damage in cells can lead to massive genomic instability that can mediate cell death [8]. To maintain DNA damage at tolerable sublethal levels, cancer cells must acquire adaptive pro-survival protective mechanisms.

DNA-dependent protein kinase, catalytic subunit (DNA-PKcs) is an enzyme encoded by PRKDC in humans [9]. It contributes to the repair of DNA double-strand breaks (DSBs) by accessing broken ends of DNA in combination with the other two DNA-binding factors, Ku70 and Ku80 [10]. This complex serves as a molecular scaffold for recruiting DNA repair factors to DNA strand breaks, such as XRCC4 and DNA ligase IV [11]. The kinase activity of DNA-PKCs is required for the non-homologous end joining (NHEJ) pathway of DNA repair, which rejoin double-strand breaks [12-14]. Phosphorylation at Thr2609 of DNA-PKcs plays a key role in NHEJ $[15,16]$. Earlier reports have shown that epidermal growth factor receptor (EGFR) plays an important role in the regulation of DNA-PKcs activity in response to radiation or anti-cancer drugs that induce DNA damage $[17,18]$. In addition, EGFR nuclear localization is required for modulation of the repair of cisplatin and ionizing radiation-induced DNA damage [17-19].

Insulin-like growth factor binding protein 2 (IGFBP2) is a member of the IGFBP's family which shares cysteine-rich amino- and carboxyterminal domains for the IGF-binding site [20]. High levels of IGFBP2 have been detected in patients' sera of some cancers with poor prognostic outcome $[21,22]$. In addition to its functions as a secretory protein, IGFBP2 intracellular oncogenic functions promote cancer cell proliferation, invasion, metastasis and drug resistance [23-25]. Interestingly, IGFBP2 protein has a nuclear localization signal sequence, which is required for its nuclear translocation to regulate cell functions or signaling pathways [26, 27]. IGFBP2 overexpression in EAC is associated with drug resistance [28]. However, its signaling and functional role in response to bile salts-induced DNA damage in esophageal tumorigenesis have not been studied.

In the present study, we investigated the expression, signaling and functional roles of IGFPB2 in response to bile salts-induced DNA damage in esophageal tumorigenesis. We detected nuclear localization and associations of IGFPB2 with EGFR-DNA-PKcs in response to acidic bile salts, a mechanism that promotes DNA damage repair and esophageal cell survival in response to the toxic effects of acidic bile salts.

\section{Methods and materials \\ Cell culture}

Three immortalized cell lines originated from Barrett's esophagus, BAR10T (kindly provided by Dr. Rhonda Souza), CPA and CPB (ATCC, Manassas, VA, USA), were cultured with DMEM/F12 (GIBCO, New York, NY, USA), supplemented with $5 \%$ fetal bovine serum (FBS, GIBCO), $1 \%$ penicillin/streptomycin (GIBCO), $0.4 \mu \mathrm{g} / \mathrm{ml}$ hydrocortisone (Sigma-Aldrich, Saint Louis, MO, USA), $20 \mathrm{mg} / \mathrm{L}$ adenine hydrochloride hydrate (Sigma-Aldrich), $140 \mu \mathrm{g} / \mathrm{ml}$ bovine pituitary extract (Thermo Fisher Scientific, Waltham, MA, USA), Insulin-transferrin-sodium selenite media supplement (Sigma-Aldrich) and $20 \mathrm{ng} / \mathrm{ml}$ recombinant epidermal growth factor (Sigma-Aldrich). EAC cell lines, FLO1 (ATCC), OE19 (Sigma-Aldrich), SK-GT4 (kindly provided by Dr. Xiaochun $\mathrm{Xu}$ at MD Anderson), ESO26 (Sigma-Aldrich) and OE33 (kindly provided by Dr. David Beer) were cultured in DMEM or RPMI 1640 medium (GIBCO), supplemented with 10\% FBS and $1 \%$ penicillin/streptomycin. All cell lines were grown at $37^{\circ} \mathrm{C}$ in $5 \% \mathrm{CO}_{2}$. Cell lines were authenticated by Genetica DNA Laboratories using short tandem repeat profiling (Genetica DNA Laboratories, Burlington, NC, USA). Cells used were from the stocks immediately after authentication and cultured less than 6 months. Mycoplasma was tested periodically using the qRT-PCR method (Southernbiotech, Birmingham, AL, USA).

\section{Chemicals}

A bile salts cocktail, consisting of an equal molar mixture of sodium salts of glycocholic acid, taurocholic acid, glycodeoxycholic acid, deoxycholic acid (CALBIOCHEM, La Jolla, CA, USA), and glycochenodeoxycholic acid (Sigma-Aldrich), was prepared to reflect the mixture of bile acids in the distal esophagus during GERD, as previously reported [29, 30]. In all experiments, $200 \mu \mathrm{M}$ final concentration of the bile salts cocktail ( $40 \mu \mathrm{M}$ of each of the above bile acids) in $\mathrm{pH} 4$ medium was used.

\section{Organotypic 3D culture}

Organotypic 3D reconstruction cultures were performed as previously described [31, 32]. Briefly, human esophageal fibroblasts (ScienCell, Carlsbad, CA, USA) were seeded into a 3D matrix $(75,000$ cells/well) containing collagen I (Corning, Tewksbury, MA, USA) and Matrigel (BD Biosciences, Franklin Lakes, NJ, USA) and were incubated for 7 days at $37^{\circ} \mathrm{C}$. Following incubation, FLO1 and OE33 cells were seeded (500,000 cells/well) on top of esophageal fibroblast matrix. Cultures were incubated 
for an additional 14 days. Cells were then treated with ABS $(\mathrm{pH} 4,200 \mu \mathrm{M})$ for $30 \mathrm{~min}$ then recovered for $1 \mathrm{~h}$. Cultures were harvested, fixed in $4 \%$ paraformaldehyde for $1 \mathrm{~h}$, and then transferred to $70 \%$ ethanol until pathological process. Sectioning of paraffin-embedded blocks and H\&E staining were processed in the Pathology Research Resource at the University of Miami.

\section{Plasmids and siRNA transfection}

The IGFBP2 expression plasmid was designed and obtained from Vectorbuilder (https://en.vectorbuilder.com/ ). IGFBP2 siRNAs were purchased from Santa Cruz Biotechnology (sc-37,195; Dallas, TX, USA) and Dharmacon (SMARTpool; Lafayette, CO, USA). The siRNA target sequences are provided in Additional file 1: Table S1. FLO1 and OE33 cells were seeded at $2 \times 10^{5}$ cells/well in 6 -well plates $24 \mathrm{~h}$ before transfection. $40 \mathrm{nM}$ siRNA or $1.5 \mu \mathrm{g}$ plasmid/well were transfected using the Lipofectamine 3000 Transfection kit (ThermoFisher).

\section{Quantitative real time RT-PCR}

Total RNA was isolated using the Direct-zol RNA MiniPrep Plus kit (ZYMO Research, Irvine, CA, USA). Single-stranded complementary DNA was synthesized using the iScript cDNA Synthesis kit (Bio-Rad, Hercules, CA, USA). Quantitative real time RT-PCR (qRT-PCR) was performed using the CFX Connect real-time system (Bio-Rad) with the threshold cycle number determined by CFX manager 3.0 software. The primer sequences for IGFBP2 are GCGAGGGCACTTGTGAGA (forward) and CCAACATGTTCATGGTGCTG (reverse). The primer sequences for EGFR are CCAGTATTGATCGGGAGAGC (forward) and TGCCTTGGCAAACTTTCTTT (reverse). Reactions were performed in triplicate. The relative mRNA expression fold was normalized to the average value of the reference gene, HPRT1, of the same sample as previously described [33, 34].

\section{Western blotting analysis}

Whole cell lysates were extracted using RIPA Lysis Buffer with proteinase and phosphatase inhibitors (Santa Cruz Biotechnology). Extraction of cytoplasmic and nuclear proteins was performed using the Cell Fractionation Kit (Cell Signaling, Danvers, MA, USA). Protein concentrations of lysates were measured by the Pierce ${ }^{\mathrm{Tx}}$ BCA Protein Assay (ThermoFisher Scientific) using a FLUO Star OPTIMA microplate reader (BMG, Cary, $\mathrm{NC}$ ). Equal amounts of proteins were loaded onto gradient $8-10 \%$ SDS-PAGE and transferred to nitrocellulose membranes (Bio-Rad). Western blotting was performed following standard procedure. The information of antibodies is provided in Additional file 1: Table S2. The ChemiDoc $^{\text {th }}$ XRS+ Imaging System (Bio-Rad) was used to capture western blot signals. Bands' intensity was measured using Image lab software (Bio-Rad). The quantification of the proteins was normalized to the intensity of $\beta$-actin of the same sample.

\section{Immunofluorescence staining}

Approximately $1 \times 10^{4}$ cells were seeded in 8-chamber Slides (Corning) $24 \mathrm{~h}$ after siRNA or plasmid transfection. Cells were treated with ABS $(\mathrm{pH} 4,200 \mu \mathrm{M})$ for 20 min and recovered for designated time points. After the treatment, cells were fixed with fresh-made $4 \%$ formaldehyde for $45 \mathrm{~min}$. Then immunofluorescence staining was performed as previously described [35]. Antibodies for IGFBP2 (Cell signaling), EGFR (Invitrogen) and Phospho-DNA-PKcs (Thr2609) (Invitrogen) were incubated at $4{ }^{\circ} \mathrm{C}$ for overnight. Alexa fluor-568 conjugated anti-rabbit and Alexa fluor-488 conjugated anti-mouse secondary antibody (Invitrogen) were incubated for $1 \mathrm{~h}$ at room temperature. Cells were mounted with DAPI solution. Images were captured using the All-in-one Fluorescence Microscope (BZ-X700) (Keyence, Itasca, IL, USA).

\section{Flow cytometry analysis of Annexin V}

To quantitate ABS-induced apoptosis, flow cytometry analysis of Annexin V were performed using a FITC Annexin V apoptosis detection kit (BD Biosciences, San Jose, CA). EAC Cells were transfected with $40 \mathrm{nM}$ IGFBP2 SMARTpool siRNA or control siRNA (Dharmacon, Lafayette, $\mathrm{CO}$ ) using LipoJet transfection reagent (SignaGen Laboratories, Rockville, MD). $48 \mathrm{~h}$ post transfection, cells were treated with $\mathrm{ABS}$ for 30 min then recovered in regular medium for $3 \mathrm{~h}$. Cells then were collected for FITC Annexin V and PI staining according to the manufacturer's instruction and subjected to flow cytometry analysis at Flow Cytometry Shared Resource at Sylvester Comprehensive Cancer Center.

\section{Co-immunoprecipitation assay}

Protein G magnetic beads (Millipore, Billerica, MA, USA) were used to capture the primary antibodies for IGFBP2, EGFR, and DNA-PKcs according to the supplier's instruction. IgG from rabbit or mouse sources (Santa Cruz Biotechnology) were used as the negative control. The same amount of protein from each group was incubated with antibody-bound beads at $4{ }^{\circ} \mathrm{C}$ overnight with continuous mixing. The beads were washed and re-suspended, on the second day, using NuPAGE ${ }^{\mathrm{mm}}$ LDS Sample Buffer (ThermoFisher) suitable for electrophoresis. Denature was performed at $90{ }^{\circ} \mathrm{C}$ for $10 \mathrm{~min}$. Western blotting analysis was performed following standard protocols. 


\section{Cycloheximide (CHX) chase assay}

Cycloheximide (CHX) is a protein synthesis inhibitor in eukaryotes, which is used in cell biology to determine the half-life of a given protein [36, 37]. FLO1 cells with IGFBP2 knockdown and control cells were treated with or without $\mathrm{ABS}$ for $20 \mathrm{~min}$ and then recovered in full medium with $50 \mu \mathrm{g} / \mathrm{ml} \mathrm{CHX.} \mathrm{Whole} \mathrm{cell} \mathrm{lysates} \mathrm{were}$ collected and analyzed using anti-EGFR antibody by Western blotting. The bands' intensities of EGFR and $\beta$-actin were measured with Bio-Rad Image lab software. The ratio of EGFR/ $\beta$-actin was obtained for each sample at different time points.

\section{Immunohistochemistry assay}

Tissue microarrays containing 60 de-identified archival cases of EACs as well as the normal esophagus, and 3 non-dysplastic BE was obtained from Tissue Pathology Core at Vanderbilt University Medical Center, Nashville, $\mathrm{TN}$. Immunohistochemical staining was performed using The IHC Select ${ }^{\circ}$ Immunoperoxidase Secondary Detection system (MilliporeSigma, Burlington, MA, USA) following manufactory's instruction. The sections were incubated with the IGFBP2 primary antibody (Cell Signaling) overnight. Immunohistochemical results were evaluated for intensity and frequency of the staining and an index score was applied as previously described [33].

\section{Statistical analysis}

Data are expressed as the mean $\pm \mathrm{SD}$ for parametric data. One-way ANOVA and Newman-Keuls test were used to compare multiple groups. Unpaired Student $t$-test was performed for two independent variables. All statistical analyses were done using GraphPad Prism 5 software. For all analyses, $P<0.05$ is considered statistically significant.

\section{Results \\ IGFBP2 is overexpressed and induced by acidic bile salts in EACs}

Using quantitative real-time RT-PCR (qRT-PCR), we detected high levels of mRNA expression of IGFPB2 in several EAC cell lines, whereas its expression is low in precancerous Barrett's cell lines (CPA, BAR10T) and Barrett's with dysplasia CPB cells (Fig. 1a). High protein expression levels of IGFBP2 was also present in 4 of 5 EAC cell lines (FLO1, OE33, OE19 and ESO26) (Fig. 1b). Next, we performed immunohistochemical staining of IGFBP2 in a tissue microarray with 60 EAC samples. As shown in Fig. 1c, normal esophageal squamous epithelia (NE) and Barrett's esophagus (BE) showed negative or weak immunostaining for IGFBP2. However, more than half of EAC tissue samples (31/57) displayed overexpression of IGFBP2 (Fig. $1 \mathrm{c}$ and d, index scores 2 and 3).
Following this finding, we hypothesized that IGFBP2 upregulation is due to adaption to acidic bile salts under GERD conditions. We, therefore, exposed EAC cells to an acidic bile salts cocktail (ABS, pH 4, 200 $\mu \mathrm{M}$ ) that closely mimics a reflux episode during GERD [29, 30] . Of note, following transient exposure of $20 \mathrm{~min}$, we detected a remarkable induction of IGFBP2 in protein and mRNA levels in FLO1 (Fig. 2a and c), OE33 (Fig. 2b and d) and OE19 (Additional file 2: Figure S1) cells. Similarly, ABS exposure also induced protein and mRNA expression of IGFBP2 in two Barrett's cell lines, CPA and BAR10T (Additional file 2: Figure S2). It has been reported that some MiRNAs (such as MiR-126) target IGFBP2 [38, 39] and bile acids induce degradation of some MiRNAs [40]. Therefore, we examined several MiRNAs known regulating IGFBP2 after ABS exposure. Indeed, $\mathrm{ABS}$ induced significant downregulation of MiR-126 in both OE33 and FLO1 cells (Additional file 2: Figure S3), suggesting that MiR-126 may play an important role in regulation of IGFBP2 in response to ABS.

To mimic the physiological and pathological conditions of GERD, we cultured EAC cells together with esophageal fibroblasts in a $3 \mathrm{D}$ organotypic culture model. We exposed 3D cultured EAC cells to ABS, and examined IGFBP2 protein expression levels using immunofluorescence assay. Data shows that IGFBP2 levels were clearly enhanced by ABS in both FLO1 (Fig. 2e) and OE33 cells (Fig. 2f) cells. The HE staining images of the organotypic cultures for FLO1 and OE33 cells are provided in Additional file 2: Figure S4.

\section{IGFBP2 protects EAC cells from acidic bile salts-induced DNA double-strand breaks and apoptosis}

Previous studies have indicated that ABS can induce DNA damage as well as apoptosis in esophageal epithelial cells $[6,41]$. Therefore, we treated EAC cells with ABS ( $\mathrm{pH} 4$, $200 \mu \mathrm{M})$ and detected an increase in double strand DNA breaks, as measured by $\gamma \mathrm{H} 2 \mathrm{AX}$ (p-H2AX, Ser139), and apoptosis, displayed as cleaved-PARP and cleaved-caspase 3 (Additional file 2: Figure S5, A (FLO1), B (OE33) and Additional file 2: Figure S1 (OE19). Immunofluorescence staining assay confirmed nuclear $\gamma \mathrm{H} 2 \mathrm{AX}$ in ABS-treated FLO1 and OE33 cells (Additional file 2: Figure S5, C and D). We next, investigated the role of IGFBP2 upregulation in protecting cancer cells from excessive ABS-induced DNA damage and apoptosis. Overexpression of IGFBP2 in OE33 cells, with relatively low endogenous level, decreased ABS-induced $\gamma \mathrm{H} 2 \mathrm{AX}$, cleaved-PARP and cleaved-caspase 3 (Fig. 3a). To confirm the role of IGFBP2, we knocked down IGFBP2 expression in FLO1 cells, with high endogenous level, and treated cells with ABS. As shown in Fig. 3b, ABS induced higher levels of $\gamma \mathrm{H} 2 \mathrm{AX}$, cleaved-PARP and cleaved-caspase 3 in IGFBP2 knockdown cells, as compared with the control cells. To 


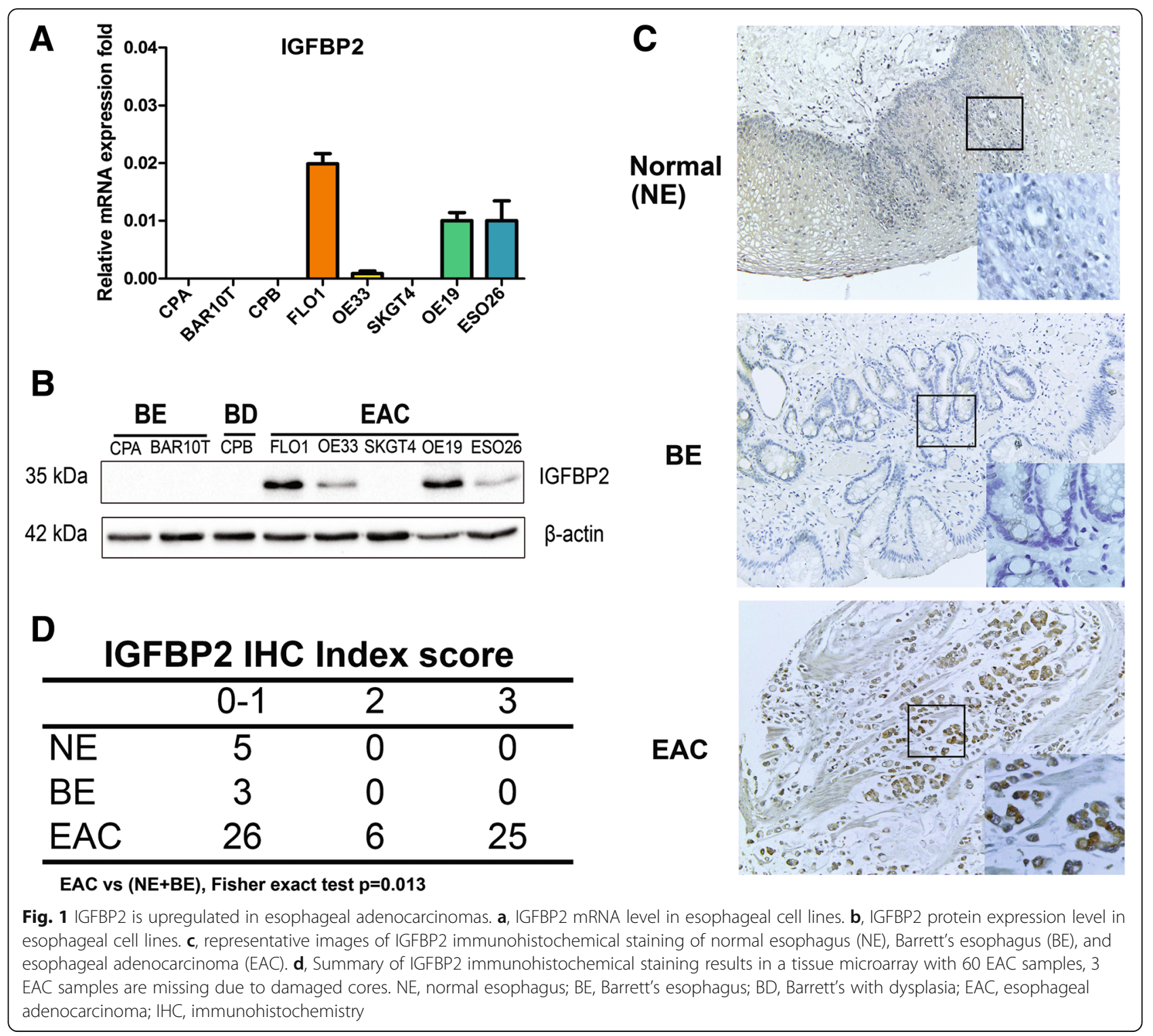

exclude the possibility of off-target effect of siRNA, we repeated the same experiment using a second IGFBP2 siRNA from a different supplier and obtained similar results (Additional file 2: Figure S6). For further validation, we confirmed these results by using immunofluorescence staining of $\gamma \mathrm{H} 2 \mathrm{AX}$ in both FLO1 (Fig. 3c and d) and OE33 (Fig. 3e and f) cells. We also performed flow cytometry analyses of annexin $\mathrm{V}$, confirming that knockdown of IGFBP2 significantly promoted ABS-induced apoptotic cell death in FLO1 cells (Fig. 3g and h), as well as in OE33 cells (Additional file 2: Figure S7).

IGFBP2 is required for acidic bile salts-induced activation of EGFR-DNA-PKcs pathway in EAC cells

To determine whether EGFR-DNA-PKcs pathway is involved in ABS-induced DNA damage repair, we examined the levels of phosphorylated EGFR (Tyr1068) and phosphorylated DNA-PKcs (Thr2609), which are representatives of enzymatic activity of EGFR and DNA-PKcs, respectively $[17,42]$. Our data showed that phosphorylation of EGFR (Tyr1068) and DNA-PKcs (Thr2609) was markedly induced by ABS in FLO1 and OE33 cells (Additional file 2: Figure S8). To determine the role of IGFBP2 in regulating the EGFR-DNA-PKCs DNA damage repair pathways, we knocked down IGFBP2 in FLO1 cells and exposed cells to ABS. As shown in Fig. 4a, knockdown of IGFBP2 attenuated ABS-induced phosphorylation of EGFR and DNA-PKcs, indicating reduced DNA repair activity of DNA-PKcs. To validate these results, we overexpressed IGFBP2 in OE33 cells and treated cells with ABS. As shown in Fig. 4b, IGFBP2 overexpression induced more phosphorylation of DNA-PKCs and EGFR in OE33 


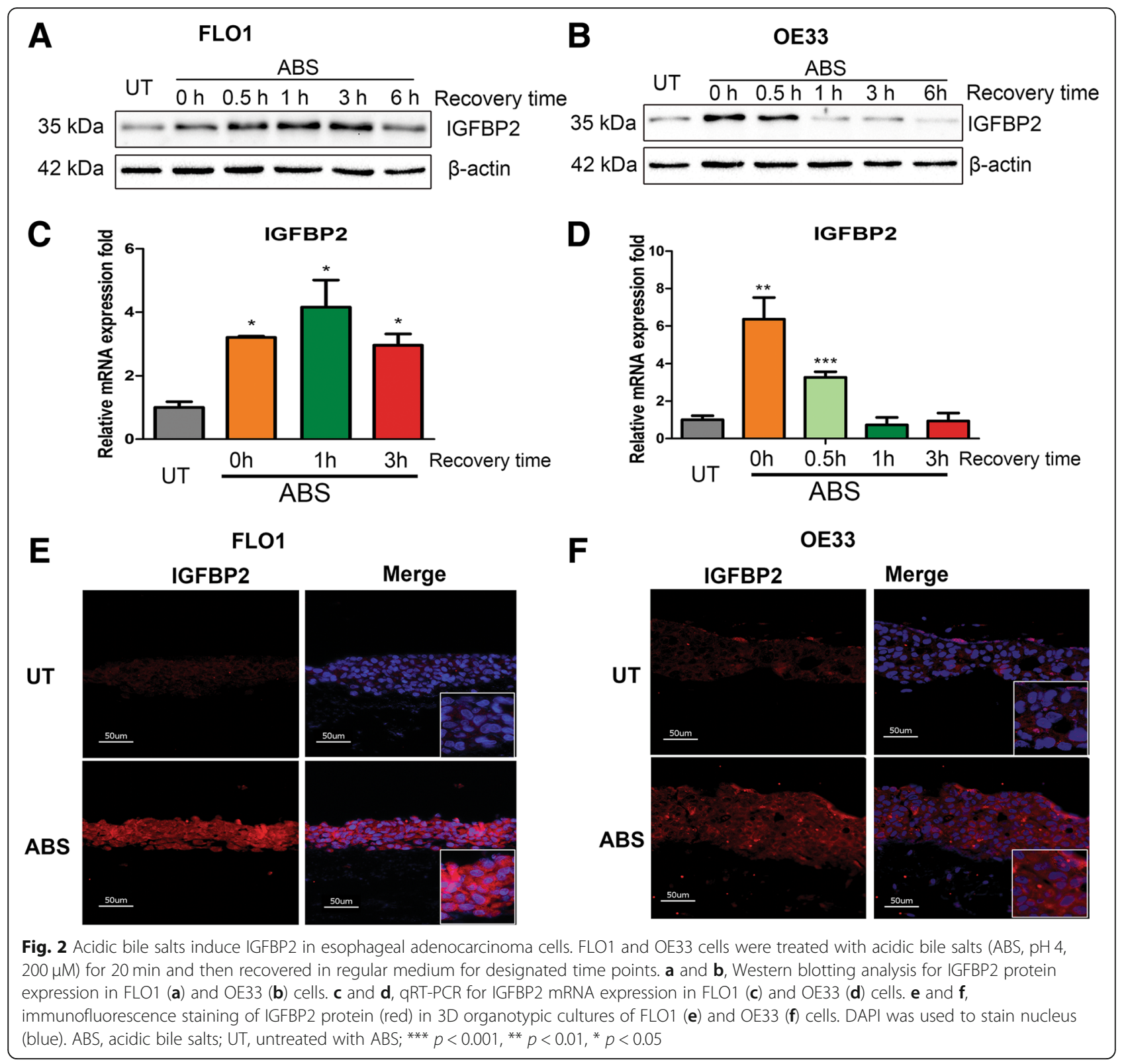

cells, following exposure to ABS, as compared to control cells. Immunofluorescence staining assay further confirmed a decrease in nuclear phospho-DNA-PKcs, following ABS exposure in IGFBP2 knockdown FLO1 cells, as compared to control cells (Fig. 4c and d). These data indicate that IGFBP2 is required for EGFR and DNA-PKCS activation in conditions of ABS exposure in EAC cells.

\section{IGFBP2 is required for nuclear accumulation and} activation of EGFR and DNA-PKcs in EAC cells in response to ABS

Earlier reports indicate that EGFR translocases into the nucleus, forms a complex with DNA-PKcs, and induces
DNA-PKcs phosphorylation, following cisplatin or radiation-induced DNA damage $[17,19]$. To examine if IGFBP2 regulates the translocation of EGFR upon ABS treatment, we extracted cytoplasmic and nuclear fractions from ABS-treated FLO1 and OE33 cells. As shown in Fig. 5a, EGFR and DNA-PKcs as well as IGFBP2 translocated into the nucleus, $30 \mathrm{~min}$ after ABS treatment in FLO1 cells. In addition, phosphorylated DNA-PKcs and EGFR proteins also accumulated in the nucleus. Similar results were obtained in OE33 cells (Additional file 2: Figure S9). To find whether IGFBP2 mediates EGFR nuclear translocation and, thus, activates DNA-PKcs, we knocked down IGFBP2 in FLO1 cells and treated cells with ABS. 

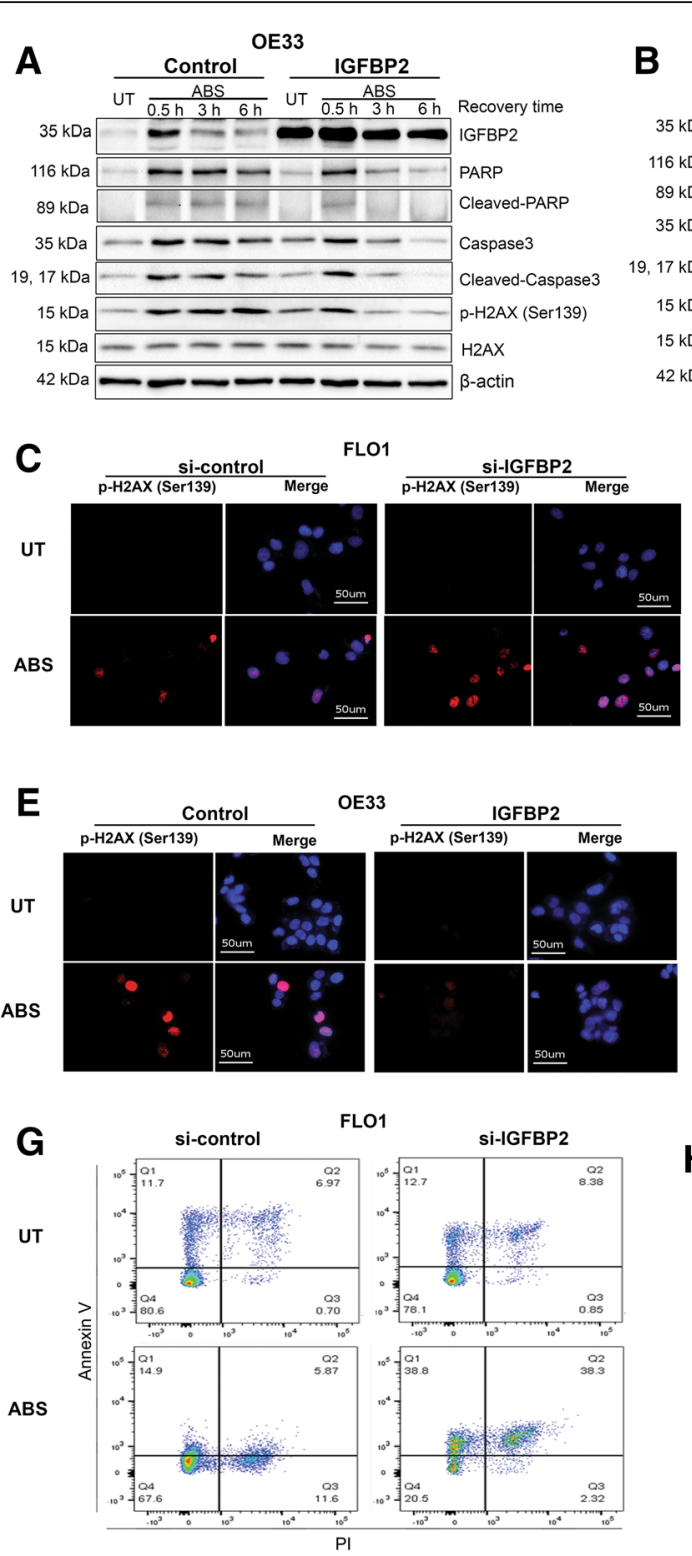

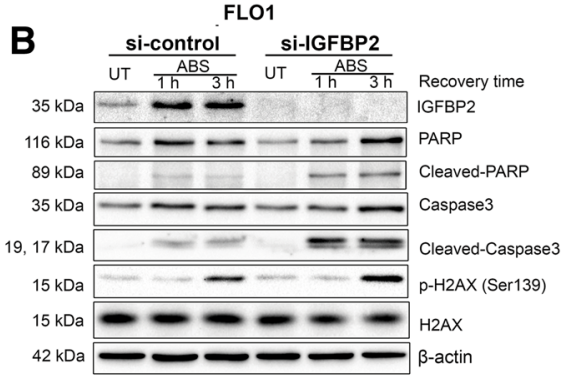

D

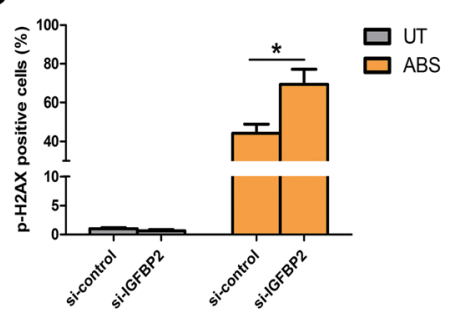

$\mathbf{F}$
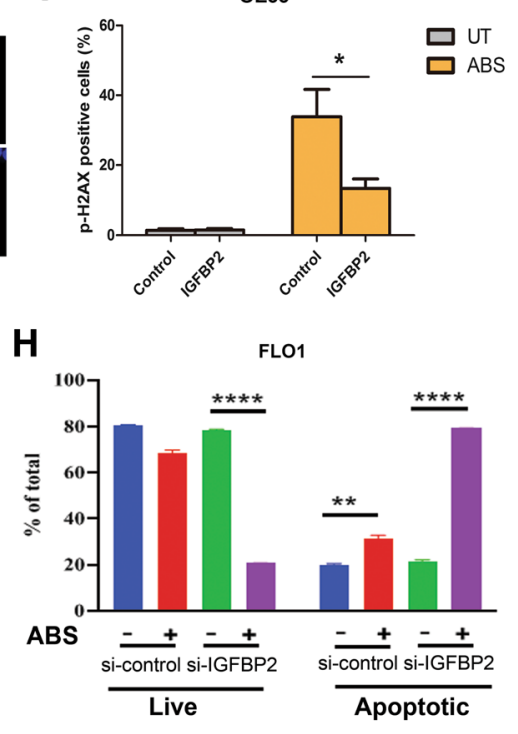

Fig. 3 IGFBP2 protects esophageal adenocarcinoma cells from acidic bile salts-induced DNA double strand breaks and apoptosis. a, OE33 cells with IGFBP2 overexpression (IGFBP2) and control cells were treated with ABS ( $\mathrm{pH} 4,200 \mu \mathrm{M})$ for $20 \mathrm{~min}$ and then recovered for the designated time points. Western blot analysis was used to detect levels of IGFBP2, caspase3, PARP and H2AX. b, FLO1 cells with IGFBP2 knockdown (siIGFBP2) and control cells (si-control) were treated with ABS for 20 min and then recovered for designated time points. Western blot analysis was used to detect levels of IGFBP2, caspase3, PARP and H2AX. c and d, FLO1 cells with IGFBP2 knockdown and control cells were treated with ABS for $20 \mathrm{~min}$ and then recovered for $3 \mathrm{~h}$. Immunofluorescence staining for p-H2AX (Ser139, red) was performed. DAPI (blue) was used to stain cell nucleus. Quantification of positive p-H2AX cells was shown in D. e and $\mathbf{f}$, OE33 cells with IGFBP2 overexpression and control cells were treated with ABS for $20 \mathrm{~min}$ and then recovered for $3 \mathrm{~h}$. Immunofluorescence staining for $\mathrm{p}-\mathrm{H} 2 \mathrm{AX}$ (Ser139, red) was performed. DAPI (blue) was used to stain cell nucleus. Quantification of positive p-H2AX cells was shown in $\mathbf{f .} \mathbf{g}$ and $\mathbf{h}$, flow cytometry analysis of Annexin V positive cells in FLO1 cells with IGFBP2 knock down or control siRNA, treated with ABS for 30 min and recovered for $3 \mathrm{~h}$. $\mathbf{g}$ shows representative flow cytometry profiles and $\mathbf{h}$ displays bar graph of live and apoptotic cells. ABS, acidic bile salts; UT, untreated with ABS. ${ }^{*} p<0.05,{ }^{* *} p<0.01,{ }^{* * * *} p<0.0001$

As shown in Fig. 5b, IGFBP2 knockdown attenuated ABS-induced nuclear accumulation of total and phosphoEGFR and DNA-PKcs. Immunofluorescence staining assays confirmed nuclear co-localization of IGFBP2 and EGFR in FLO1 cells, following treatment with
ABS (Fig. 5c). Nuclear EGFR was hardly visible, following knockdown of IGFBP2.

Earlier studies have suggested that EGFR phosphorylation at Tyr1068 is required for its nuclear translocation in response to cisplatin-induced DNA damage [19, 43]. 


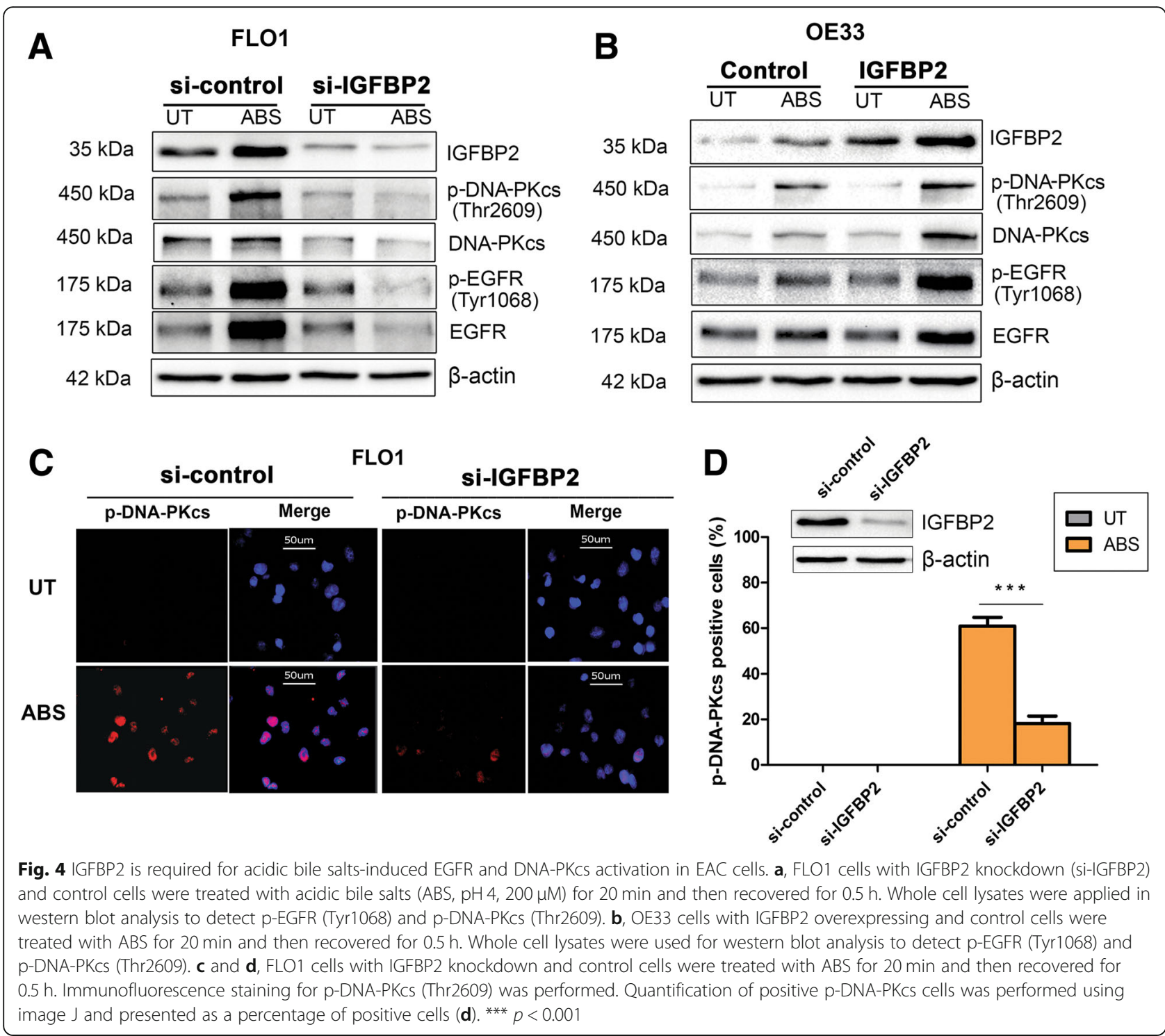

We, therefore, used tyrosine kinase inhibitor, gefitinib, to examine whether phosphorylation of EGFR is required for its nuclear translocation in response to ABS. As shown in Fig. 5d, treatment with gefitinib attenuated EGFR nuclear accumulation in response to ABS. As expected, less phospho-DNA-PKcs in the nucleus was also observed in gefitinib-treated cells. To confirm that the DNA damage repair function of IGFBP2 is mediated by EGFR, we performed rescue experiments by overexpressing IGFPB2 in OE33 cells, followed by treatment with ABS and gefitinib (Fig. 5e). Overexpression of IGFBP2 enhanced p-EGFR and inhibited ABS-induced cleaved PARP and p-H2AX. However, administration of gefitinib abrogated the protective function of IGFBP2 and impaired ABS-induced phosphorylation of EGFR with a notable increase in the ABS-induced cleaved PARP and p-H2AX levels.
IGFBP2 forms a complex with EGFR and DNA-PKcs in EAC cells in response to $A B S$

Based on our findings, we hypothesized that IGFBP2 regulates EGFR and DNA-PKcs pathway through enhanced binding with this complex, under ABS exposure conditions. We carried out co-immunoprecipitation assays (co-IP) using antibodies against EGFR, DNA-PKcs, and IGFBP2. As shown in Fig. 6a (FLO1) and 6B (OE33), the co-IP assay showed that IGFBP2, EGFR, and DNA-PKcs co-exist in the same protein complex, markedly enhanced after ABS treatment. To prove that IGFBP2 is required for the interaction between EGFR and DNA-PKCs, under ABS exposure conditions, we repeated co-IP for EGFR, following IGFBP2 knockdown and ABS treatment. As shown in Fig. 6c, IGFBP2 knockdown in FLO1 cells led to a remarkable reduction in the interaction between EGFR and DNA-PKcs, as compared with control cells. 


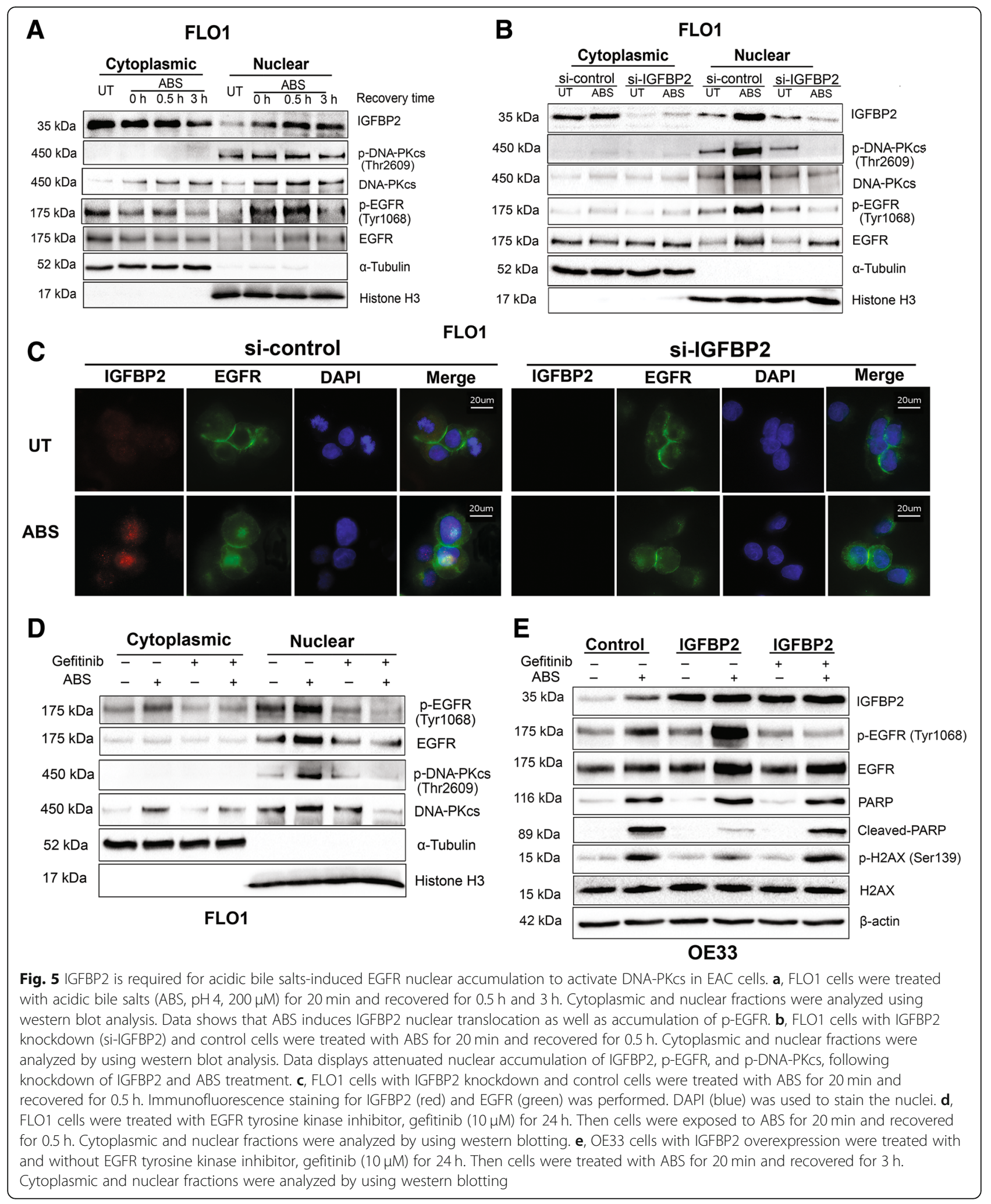




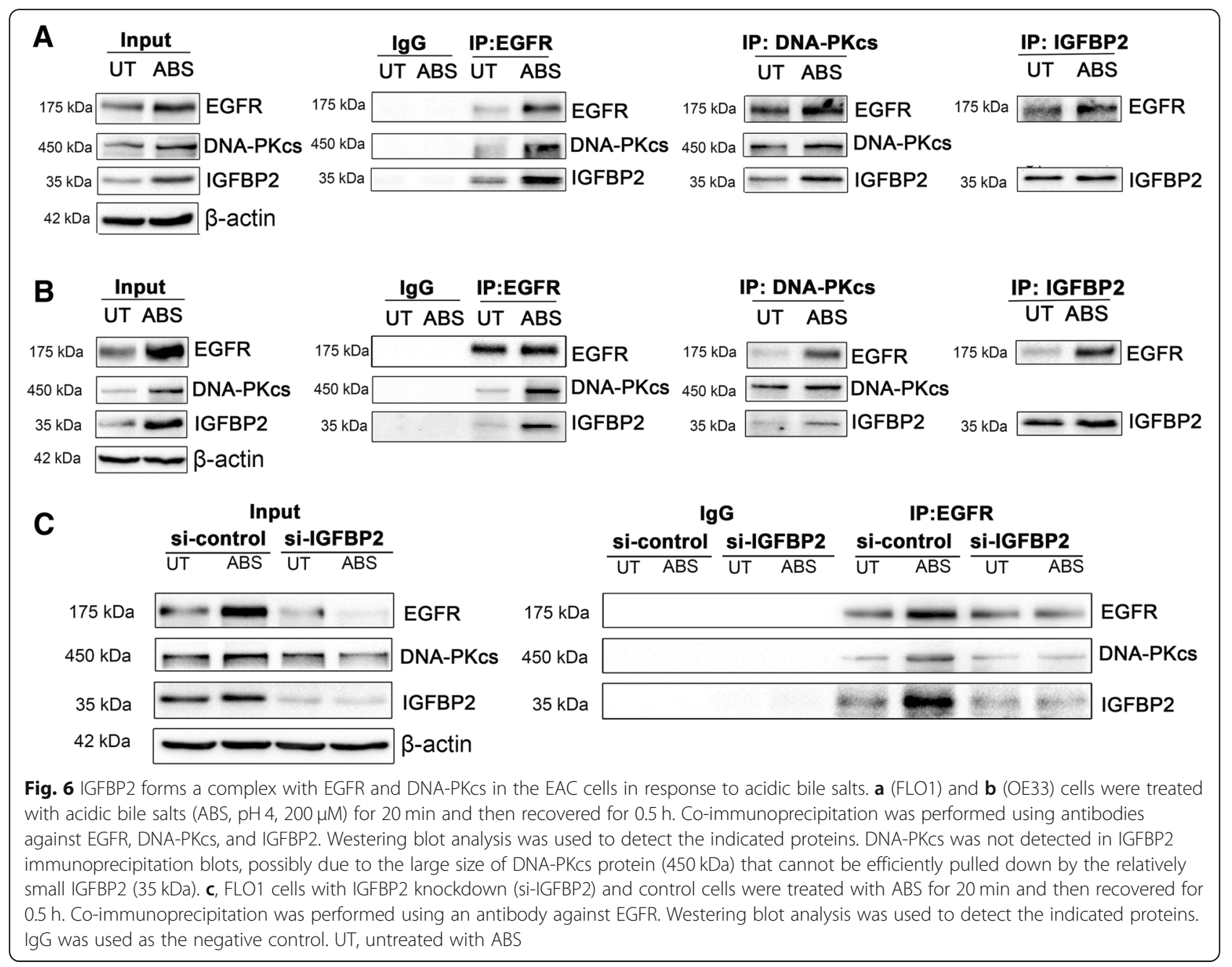

\section{IGFBP2 is required for stabilization of EGFR after ABS} treatment in EAC cells

Because we observed that ABS induced a significant upregulation of EGFR protein, whereas the EGFR induction was impaired in cells with IGFBP2 knockdown (Fig. 4), we examined mRNA levels of EGFR in control and IGFBP2 knockdown FLO1 cells. Knockdown of IGFBP2 did not affect mRNA levels of EGFR without or with ABS treatment (Additional file 2: Figure S10). We therefore hypothesized that the observed differences in EGFR protein levels in IGFBP2 control and knockdown cells are likely due to changes in EGFR protein stability under cellular stress conditions. To confirm this, FLO1 cells with IGFBP2 knockdown and control cells were treated with or without ABS, and then recovered in full medium with cycloheximide (CHX, $50 \mu \mathrm{g} / \mathrm{ml})$ for $0,1,24$ and 48 $\mathrm{h}$ to block protein synthesis. Western blot assay was used to detect changes in the EGFR protein degradation rate. As shown in Fig. 7, a and b, ABS treatment stabilized EGFR proteins, at least up to $48 \mathrm{~h}$ (average EGFR/ actin ratio 0.83 in ABS treated cells as compared to 0.32 in ABS untreated si-control cells, $p<0.001)$. Knockdown IGFBP2 alone in FLO1 cells slightly decreased EGFR protein stability as compared to control cells (EGFR/actin ratio 0.32 in si-control cells vs 0.14 in si-IGFBP2 cells at $48 \mathrm{~h}$ time point, $p<0.01$ ). However, when cells without IGFBP2 (si-IGFBP2) were under stress with ABS treatment, EGFR proteins degraded more rapidly than that without $\mathrm{ABS}$ treatment (EGFR/actin ratio 0.12 in cells with $\mathrm{ABS}$ vs 0.51 in cells without $\mathrm{ABS}$ at $24 \mathrm{~h}$ time point, $\mathrm{p}<0.001)$. These data suggest that IGFPB2 plays a role in stabilizing EGFR protein under ABS stress conditions.

\section{Discussion}

Chronic gastroesophageal reflux disease, where acidic bile salts abnormally reflux into the lower esophagus, is a major risk factor for the development of Barrett's esophagus and EAC $[4,44]$. Acidic bile salts induce high levels of oxidative stress that damage cellular components including proteins, lipids, and DNA [45]. This cellular stress environment persists along the stages of $\mathrm{BE}$ and its progression to EAC $[5,6,46]$. Therefore, EAC cells must 


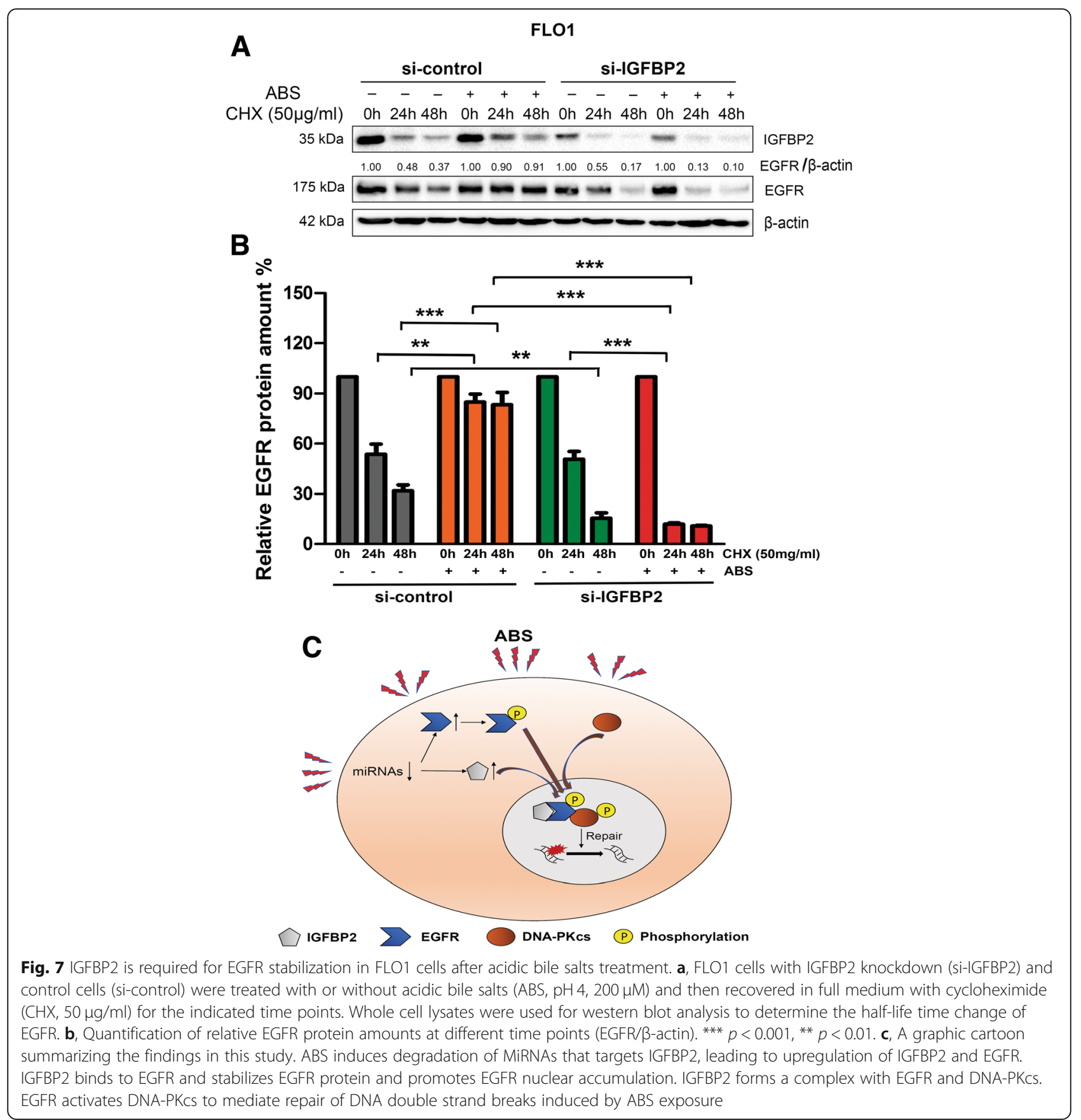

develop adaptation mechanisms to overcome this toxic environment, promote cell survival, and maintain DNA damage below lethal levels. In this study, we discovered that IGFBP2 is expressed at high levels in EAC tissues and cell lines. We also found that IGFPB2 is further induced in both mRNA and protein levels in EAC cells following exposure to ABS. Our findings demonstrate that IGFBP2, under ABS-induced stress condition, promotes stability and nuclear translocation of EGFR and co-exists with EFGR-DNA-PKcs protein complex, essential for DNA repair under stress condition.
IGFBP2 was originally discovered in serum for its binding to IGF1/2, ligands for IGF1R, to maintain activation of the IGF1R signaling pathway $[47,48]$. Although IGFBP2 is a secretory protein, IGFBP2 has a nuclear translocation sequence, necessary for its import into the nucleus [26]. Overexpression of intracellular IGFBP2 has been described in several human cancers where it is associated with cellular proliferation, progression and drug-resistance [25-27]. In this study, we detected high levels of IGFPB2 in EAC tissues and in vitro cell models, suggesting a possible role in Barrett's esophageal tumorigenesis. We focused our 
studies on the mechanistic relationship between IGFBP2 and ABS, a major etiological risk factor that underlies the biology of EAC. Because acidic bile salts induce high levels of ROS and DNA damage [6, 7], EAC cells must evolve to endure this harsh environment for survival. Our data indicate that IGFBP2 protects against ABS-induced double strand breaks and may thus favor tumor cell survival under reflux conditions.

In response to DNA damage caused by anti-cancer drugs or radiation, DNA-PKCs is phosphorylated at Thr2609, an essential step for its DNA repair capacity $[15,16]$. DNA-PKcs recruits other DNA damage repair proteins such as Ku70 and Ku80, XLF, XRCC4 and LigIV to repair damaged DNA [11]. We found that phosphorylation of DNA-PKcs at Thr2609, following ABS, was regulated by levels of IGFBP2. Earlier studies suggested that EGFR binds to DNA-PKcs and induces its phosphorylation $[19,42]$. In agreement with this note, our data suggest that IGFBP2 is required for stabilization and nuclear translocation of EGFR, and is required for formation of the EGFR-DNA-PKcs nuclear complex. Of note, we found that the interaction between IGFPB2 and the EGFR-DNA-PKcs complex is markedly enhanced, in response to ABS-induced stress. However, the precise mechanism by which IGFBP2 stabilizes EGFR under ABS stress conditions warrants further investigations.

We postulated that induction of IGFBP2 in response to ABS could be due to regulation of miRNAs. An earlier study has shown that MiR-126 can target IGFBP2 for degradation [38]. Our studies demonstrated that MiR-126 is significantly downregulated in response to ABS, inversely correlating with IGFBP2 levels. This finding provides a plausible mechanism for regulation of IGFBP2 in our system. It is also possible that a similar mechanism may be involved in regulation of EGFR in response to ABS, such as MiR-141 [49]. Of note, downregulation of MiR-141 has been reported in Barrett's esophagus [50]. However, further studies are needed to validate this mechanism.

IGFBP2 is a secretory protein with high levels in the serum of patients with several types of cancer [21, 22, 51]. High levels of IGFBP2 in patients' sera predicted poor prognostic outcome [21, 22]. Therefore, the high levels of IGFBP2 in EAC may also have a promising application in diagnosis and / or prognosis in patients with EAC. A comprehensive large size clinical study is needed to clarify this note. In addition, targeting the IGFBP2-EGFR-DNA-PKcs signaling axis may be beneficial in patients with EAC. EGFR inhibitors are used in the treatment of selected cancer patients; especially those with non-small cell lung cancer [52, 53]. A number of experimental DNA-PK inhibitors, such as NU7026, are also under investigation for various cancers $[54,55]$. Considering the role of IGFBP2 in forming the complex with EGFR and DNA-PKcs in DNA damage or drug resistance in EAC, the use of EGFR,
DNA-PKcs inhibitors or the development of specific IGFBP2 inhibitors will be a promising therapeutic strategy as single agents or in combination with DNA damaging anti-cancer agents.

\section{Conclusions}

We have discovered that IGFBP2 is overexpressed in EAC and $\mathrm{ABS}$ induces IGFBP2 probably through degradation of MiRNAs targeting IGFBP2. IGFBP2 protects EAC cells from $\mathrm{ABS}$-induced DNA damage and apoptosis through activating nuclear EGFR-DNA-PKcs pathway. IGFBP2 promotes stabilization of EGFR protein levels and interacts with the EGFR-DNA-PKcs complex to promote DNA repair and cancer cell survival (a graphic summary is shown in Fig. 7c).

\section{Additional files}

Additional file 1: Table S1. IGFBP2 siRNAs target sequences. Table S2. Information of antibodies used in this study. (PDF $65 \mathrm{~kb}$ )

Additional file 2: Figure S1. ABS induce IGFBP2, DNA damage and apoptosis in OE19 cells; Figure S2. ABS induced IGFBP2 in Barrett's cells; Figure S3. ABS induced MiR-126 degradation in EAC cells; Figure S4. HE staining of FLO1 and OE33 in 3D organotypic culture model; Figure S5. ABS induce DNA damage and apoptosis in EAC cells; Figure S6. Knockdown of IGFBP2 using a second IGFBP2 siRNA; Figure S7. Flow cytometry analysis of Annexin $V$ in OE33 cells; Figure S8. ABS activate EGFR-DNA-PKCS pathway in EAC cells; Figure S9. ABS induce IGFBP2, EGFR and DNA-PKCs nuclear accumulation in OE33 cells; Figure S10. IGFBP2 knockdown does not affect EGFR mRNA expression. (PDF 5939 kb)

\section{Abbreviations}

ABS: acidic bile salts; ANOVA: analysis of variance; BE: Barrett's esophagus; CHX: cycloheximide; co-IP: co-immunoprecipitation assay; DNA-PKcs: DNAdependent protein kinase, catalytic subunit; DSBs: double-strand breaks; EAC: esophageal adenocarcinoma; EGFR: epidermal growth factor receptor; GERD: gastroesophageal reflux disease; IGFBP2: insulin-like growth factor binding protein 2; $\mathrm{HC}$ : immunohistochemistry; NHEJ: non-homologous end joining; qRT-PCR: quantitative real time reverse transcription-polymerase chain reaction; RIPA: radioimmunoprecipitation; ROS: reactive oxygen species

\section{Acknowledgements}

The authors gratefully acknowledge financial support from the China Scholarship Council. The content of this work is solely the responsibility of the authors and do not necessarily represent the official views of the Department of Veterans Affairs, National Institutes of Health, or the University of Miami.

\section{Funding}

This study was supported by development funds from Sylvester Comprehensive Cancer Center, and grants from the U.S. National Institutes of Health (R01CA206563 and R01CA224366) and the U.S. Department of Veterans affairs (1IK6BX003787 and 101BX001179).

\section{Availability of data and materials}

All data generated or analyzed during this study are included in this published article and its supplementary information files.

\section{Authors' contributions}

ZZ designed methodology, performed research, analyzed data and wrote the manuscript; HL, SZ, ZC, AG and JY contributed new reagents or analytic tools and results interpretation; KW performed histology and tissue microarray analysis; WER, CD and DP designed research, interpretated results, supervised research and manuscript writing. 


\section{Ethics approval and consent to participate}

All de-identified tissue samples were obtained from the archives of pathology at Vanderbilt University (Nashville, Tennessee, USA). The use of specimens from the tissue repository was approved by the Vanderbilt institutional review board.

\section{Consent for publication}

Not applicable.

\section{Competing interests}

The authors declare that they have no competing interests.

\section{Publisher's Note}

Springer Nature remains neutral with regard to jurisdictional claims in published maps and institutional affiliations.

\section{Author details \\ 'Department of Surgical Oncology, the First Affiliated Hospital of Xi'an Jiaotong University, 277 Yanta W. Road, Xi'an 710061, Shaanxi, China. ${ }^{2}$ Department of Surgery, University of Miami Miller School of Medicine, Miami, FL 33136-1015, USA. ${ }^{3}$ Sylvester Comprehensive Cancer Center, University of Miami Miller School of Medicine, Miami, FL 33136-1015, USA. ${ }^{4}$ Department of Veterans Affairs, Miami Healthcare System, Miami, FL, USA. ${ }^{5}$ Department of Gastroenterology, the First Affiliated Hospital of Nanjing Medical University, Nanjing, China. ${ }^{6}$ Department of Pathology, Microbiology and Immunology, Vanderbilt University Medical Center, Nashville, TN, USA.}

Received: 12 October 2018 Accepted: 26 December 2018

Published online: 09 January 2019

\section{References}

1. Hur C, Miller M, Kong CY, Dowling EC, Nattinger KJ, Dunn M, et al. Trends in esophageal adenocarcinoma incidence and mortality. Cancer. 2013;119(6):1149-58.

2. Thrift AP, Whiteman DC. The incidence of esophageal adenocarcinoma continues to rise: analysis of period and birth cohort effects on recent trends. Ann Oncol. 2012;23(12):3155-62.

3. Shaheen NJ, Richter JE. Barrett's oesophagus. Lancet. 2009;373(9666):850-61.

4. Kountourakis P, Ajani JA, Davila M, Lee JH, Bhutani MS, Izzo JG. Barrett's esophagus: a review of biology and therapeutic approaches. Gastrointest Cancer Res. 2012;5(2):49-57.

5. Dvorak K, Payne CM, Chavarria M, Ramsey L, Dvorakova B, Bernstein H, et al. Bile acids in combination with low pH induce oxidative stress and oxidative DNA damage: relevance to the pathogenesis of Barrett's oesophagus. Gut. 2007:56(6):763-71.

6. Hong J, Chen Z, Peng D, Zaika A, Revetta F, Washington MK, et al. APE1-mediated DNA damage repair provides survival advantage for esophageal adenocarcinoma cells in response to acidic bile salts. Oncotarget. 2016;7(13):16688-702.

7. Peng D, Belkhiri A, Hu T, Chaturvedi R, Asim M, Wilson KT, et al. Glutathione peroxidase 7 protects against oxidative DNA damage in oesophageal cells. Gut. 2012;61(9):1250-60.

8. Khanna KK, Jackson SP. DNA double-strand breaks: signaling, repair and the cancer connection. Nat Genet. 2001:27(3):247-54

9. Collis SJ, DeWeese TL, Jeggo PA, Parker AR. The life and death of DNA-PK. Oncogene. 2005;24(6):949-61.

10. Davis AJ, Chen BP, Chen DJ. DNA-PK: a dynamic enzyme in a versatile DSB repair pathway. DNA repair. 2014;17:21-9.

11. Drouet J, Delteil C, Lefrancois J, Concannon P, Salles B, Calsou P. DNAdependent protein kinase and XRCC4-DNA ligase IV mobilization in the cell in response to DNA double strand breaks. J Biol Chem. 2005;280(8):7060-9.

12. Yang K, Guo R. Xu D. non-homologous end joining: advances and frontiers. Acta Biochim Biophys Sin Shanghai. 2016;48(7):632-40.

13. Harnor SJ, Brennan A, Cano C. Targeting DNA-dependent protein kinase for Cancer therapy. ChemMedChem. 2017;12(12):895-900.

14. Chen BP, Li M, Asaithamby A. New insights into the roles of ATM and DNA-PKcs in the cellular response to oxidative stress. Cancer Lett. 2012; 327(1-2):103-10.

15. Chan DW, Chen BP, Prithivirajsingh S, Kurimasa A, Story MD, Qin J, et al. Autophosphorylation of the DNA-dependent protein kinase catalytic subunit is required for rejoining of DNA double-strand breaks. Genes Dev. 2002;16(18):2333-8.
16. Block WD, Yu Y, Merkle D, Gifford JL, Ding Q, Meek K, et al. Autophosphorylation-dependent remodeling of the DNA-dependent protein kinase catalytic subunit regulates ligation of DNA ends. Nucleic Acids Res. 2004:32(14):4351-7.

17. Dittmann K, Mayer C, Fehrenbacher B, Schaller M, Raju U, Milas L, et al. Radiation-induced epidermal growth factor receptor nuclear import is linked to activation of DNA-dependent protein kinase. J Biol Chem. 2005; 280(35):31182-9.

18. Bandyopadhyay D, Mandal M, Adam L, Mendelsohn J, Kumar R. Physical interaction between epidermal growth factor receptor and DNA-dependent protein kinase in mammalian cells. J Biol Chem. 1998;273(3):1568-73.

19. Liccardi G, Hartley JA. Hochhauser D. EGFR nuclear translocation modulates DNA repair following cisplatin and ionizing radiation treatment. Cancer Res. 2011;71(3):1103-14.

20. Clemmons DR. IGF binding proteins and their functions. Mol Reprod Dev. 1993;35(4):368-74 discussion 74-5.

21. Russell MR, Graham C, D'Amato A, Gentry-Maharaj A, Ryan A, Kalsi JK, et al. A combined biomarker panel shows improved sensitivity for the early detection of ovarian cancer allowing the identification of the most aggressive type II tumours. Br J Cancer. 2017;117(5):666-74.

22. Hur H, Yu EJ, Ham IH, Jin HJ, Lee D. Preoperative serum levels of insulin-like growth factor-binding protein 2 predict prognosis of gastric cancer patients. Oncotarget. 2017;8(7):10994-1003.

23. Tang D, Yao R, Zhao D, Zhou L, Wu Y, Yang Y, et al. Trichostatin a reverses the chemoresistance of lung cancer with high IGFBP2 expression through enhancing autophagy. Sci Rep. 2018;8(1):3917.

24. Zhang L, Huang W, Chen J, Zhou X, Lu Z, Zhou H. Expression of IGFBP2 in gastric carcinoma and relationship with clinicopathologic parameters and cell proliferation. Dig Dis Sci. 2007;52(1):248-53.

25. Migita T, Narita T, Asaka R, Miyagi E, Nagano H, Nomura K, et al. Role of insulin-like growth factor binding protein 2 in lung adenocarcinoma: GF-independent antiapoptotic effect via caspase-3. Am J Pathol. 2010; 176(4):1756-66.

26. Azar WJ, Zivkovic S, Werther GA, Russo VC. IGFBP-2 nuclear translocation is mediated by a functional NLS sequence and is essential for its protumorigenic actions in cancer cells. Oncogene. 2014:33(5):578-88.

27. Li X, Liu X, Zhang L, Li C, Zhang E, Ma W, et al. Insulin growth factor binding protein 2 mediates the progression of lymphangioleiomyomatosis. Oncotarget. 2017;8(22):36628-38

28. Myers AL, Lin L, Nancarrow DJ, Wang Z, Ferrer-Torres D, Thomas DG, et al. IGFBP2 modulates the chemoresistant phenotype in esophageal adenocarcinoma. Oncotarget. 2015;6(28):25897-916.

29. Nehra D, Howell P, Williams CP, Pye JK, Beynon J. Toxic bile acids in gastrooesophageal reflux disease: influence of gastric acidity. Gut. 1999:44(5):598-602

30. Kauer WK, Peters JH, DeMeester TR, Feussner $\mathrm{H}$, Ireland AP, Stein HJ, et al. Composition and concentration of bile acid reflux into the esophagus of patients with gastroesophageal reflux disease. Surgery. 1997;122(5):874-81.

31. Le Bras GF, Loomans HA, Taylor CJ, Revetta FL, Andl CD. Activin a balance regulates epithelial invasiveness and tumorigenesis. Lab Invest. 2014;94(10):1134-46.

32. Chen Z, Hu T, Zhu S, Mukaisho K, El-Rifai W, Peng DF. Glutathione peroxidase 7 suppresses cancer cell growth and is hypermethylated in gastric cancer. Oncotarget. 2017:8(33):54345-56.

33. Peng DF, Razvi M, Chen H, Washington K, Roessner A, Schneider-Stock R, et al. DNA hypermethylation regulates the expression of members of the muclass glutathione S-transferases and glutathione peroxidases in Barrett's adenocarcinoma. Gut. 2009;58(1):5-15.

34. El-Rifai W, Moskaluk CA, Abdrabbo MK, Harper J, Yoshida C, Riggins GJ, et al. Gastric cancers overexpress S100A calcium-binding proteins. Cancer Res. 2002;62(23):6823-6

35. Soutto M, Peng D, Katsha A, Chen Z, Piazuelo MB, Washington MK, et al. Activation of beta-catenin signalling by TFF1 loss promotes cell proliferation and gastric tumorigenesis. Gut. 2015;64(7):1028-39

36. Kao SH, Wang WL, Chen CY, Chang YL, Wu YY, Wang YT, et al. Analysis of protein stability by the Cycloheximide chase assay. Bio Protoc. 2015;5(1)

37. Schneider-Poetsch T, Ju J, Eyler DE, Dang Y, Bhat S, Merrick WC, et al. Inhibition of eukaryotic translation elongation by cycloheximide and lactimidomycin. Nat Chem Biol. 2010:6(3):209-17.

38. Png KJ, Halberg N, Yoshida M, Tavazoie SFA. microRNA regulon that mediates endothelial recruitment and metastasis by cancer cells. Nature. 2011;481(7380):190-4. 
39. Peng T, Zhou L, Qi H, Wang G, Luan Y, Zuo L. MiR-592 functions as a tumor suppressor in glioma by targeting IGFBP2. Tumour Biol. 2017;39(7): 1010428317719273.

40. Doukas SG, Vageli DP, Sasaki CT. NF-kappaB inhibition reverses acidic bileinduced miR-21, miR-155, miR-192, miR-34a, miR-375 and miR-451a deregulations in human hypopharyngeal cells. J Cell Mol Med. 2018;22(5): 2922-34.

41. Zhang HY, Hormi-Carver K, Zhang X, Spechler SJ, Souza RF. In benign Barrett's epithelial cells, acid exposure generates reactive oxygen species that cause DNA double-strand breaks. Cancer Res. 2009;69(23):9083-9.

42. Javvadi P, Makino H, Das AK, Lin YF, Chen DJ, Chen BP, et al. Threonine 2609 phosphorylation of the DNA-dependent protein kinase is a critical prerequisite for epidermal growth factor receptor-mediated radiation resistance. Mol Cancer Res. 2012;10(10):1359-68.

43. Friedmann BJ, Caplin M, Savic B, Shah T, Lord CJ, Ashworth A, et al. Interaction of the epidermal growth factor receptor and the DNAdependent protein kinase pathway following gefitinib treatment. Mol Cancer Ther. 2006;5(2):209-18.

44. Shaheen N, Ransohoff DF. Gastroesophageal reflux, Barrett esophagus, and esophageal cancer: scientific review. JAMA. 2002;287(15):1972-81.

45. Bhattacharyya A, Chattopadhyay R, Mitra S, Crowe SE. Oxidative stress: an essential factor in the pathogenesis of gastrointestinal mucosal diseases. Physiol Rev. 2014;94(2):329-54.

46. Olyaee M, Sontag S, Salman W, Schnell T, Mobarhan S, Eiznhamer D, et al. Mucosal reactive oxygen species production in oesophagitis and Barrett's oesophagus. Gut. 1995:37(2):168-73.

47. Hwa V, Oh Y, Rosenfeld RG. The insulin-like growth factor-binding protein (IGFBP) superfamily. Endocr Rev. 1999;20(6):761-87.

48. Jones Jl, Clemmons DR. Insulin-like growth factors and their binding proteins: biological actions. Endocr Rev. 1995;16(1):3-34.

49. Wang J, Wang G, Li B, Qiu C, He M. miR-141-3p is a key negative regulator of the EGFR pathway in osteosarcoma. Onco Targets Ther. 2018;11:4461-78.

50. Smith CM, Watson DI, Leong MP, Mayne GC, Michael MZ, Wijnhoven BP, et al. miR-200 family expression is downregulated upon neoplastic progression of Barrett's esophagus. World J Gastroenterol. 2011:17(8):1036-44.

51. Kendrick ZW, Firpo MA, Repko RC, Scaife CL, Adler DG, Boucher KM, et al. Serum IGFBP2 and MSLN as diagnostic and prognostic biomarkers for pancreatic cancer. HPB (Oxford). 2014;16(7):670-6.

52. Rosell R, Carcereny E, Gervais R, Vergnenegre A, Massuti B, Felip E, et al. Erlotinib versus standard chemotherapy as first-line treatment for European patients with advanced EGFR mutation-positive non-small-cell lung cancer (EURTAC): a multicentre, open-label, randomised phase 3 trial. Lancet Oncol. 2012;13(3):239-46.

53. Zhou C, Wu YL, Chen G, Feng J, Liu XQ, Wang C, et al. Erlotinib versus chemotherapy as first-line treatment for patients with advanced EGFR mutation-positive non-small-cell lung cancer (OPTIMAL, CTONG-0802): a multicentre, open-label, randomised, phase 3 study. Lancet Oncol. 2011; 12(8):735-42.

54. Willmore E, de Caux S, Sunter NJ, Tilby MJ, Jackson GH, Austin CA, et al. A novel DNA-dependent protein kinase inhibitor, NU7026, potentiates the cytotoxicity of topoisomerase II poisons used in the treatment of leukemia. Blood. 2004;103(12):4659-65.

55. Nutley BP, Smith NF, Hayes A, Kelland LR, Brunton L, Golding BT, et al. Preclinical pharmacokinetics and metabolism of a novel prototype DNA-PK inhibitor NU7026. Br J Cancer. 2005;93(9):1011-8.

Ready to submit your research? Choose BMC and benefit from:

- fast, convenient online submission

- thorough peer review by experienced researchers in your field

- rapid publication on acceptance

- support for research data, including large and complex data types

- gold Open Access which fosters wider collaboration and increased citations

- maximum visibility for your research: over $100 \mathrm{M}$ website views per year

At BMC, research is always in progress.

Learn more biomedcentral.com/submissions 